\title{
Technical Note: Evaluation of the WRF-Chem "Aerosol Chemical to Aerosol Optical Properties" Module using data from the MILAGRO campaign
}

\author{
J. C. Barnard ${ }^{1}$, J. D. Fast ${ }^{1}$, G. Paredes-Miranda ${ }^{2}$, W. P. Arnott ${ }^{2}$, and A. Laskin ${ }^{1}$ \\ ${ }^{1}$ Pacific Northwest National Laboratory, Richland, Washington, USA \\ ${ }^{2}$ University of Nevada, Reno, Nevada, USA
}

Received: 4 March 2010 - Published in Atmos. Chem. Phys. Discuss.: 7 April 2010

Revised: 9 July 2010 - Accepted: 21 July 2010 - Published: 9 August 2010

\begin{abstract}
A comparison between observed aerosol optical properties from the MILAGRO field campaign, which took place in the Mexico City Metropolitan Area (MCMA) during March 2006, and values simulated by the Weather Research and Forecasting (WRF-Chem) model, reveals large differences. To help identify the source of the discrepancies, data from the MILAGRO campaign are used to evaluate the "aerosol chemical to aerosol optical properties" module implemented in the full chemistry version of the WRF-Chem model. The evaluation uses measurements of aerosol size distributions and chemical properties obtained at the MILAGRO T1 site. These observations are fed to the module, which makes predictions of various aerosol optical properties, including the scattering coefficient, $B_{\text {scat }}$; the absorption coefficient, $B_{\mathrm{abs}}$; and the single-scattering albedo, $\varpi_{0}$; all as a function of time. Values simulated by the module are compared with independent measurements obtained from a photoacoustic spectrometer (PAS) at a wavelength of $870 \mathrm{~nm}$. Because of line losses and other factors, only "fine mode" aerosols with aerodynamic diameters less than $2.5 \mu \mathrm{m}$ are considered here. Over a 10-day period, the simulations of hour-by-hour variations of $B_{\text {scat }}$ are not satisfactory, but simulations of $B_{\mathrm{abs}}$ and $\varpi_{0}$ are considerably better. When averaged over the 10-day period, the computed and observed optical properties agree within the uncertainty limits of the measurements and simulations. Specifically, the observed and calculated values are, respectively: (1) $B_{\text {scat }}, 34.1 \pm 5.1 \mathrm{Mm}^{-1}$ versus $30.4 \pm 3.4 \mathrm{Mm}^{-1}$; (2) $B_{\text {abs }}, 9.7 \pm 1.0 \mathrm{Mm}^{-1}$ versus $11.7 \pm 1.2 \mathrm{Mm}^{-1}$; and (3) $\varpi_{0}, 0.78 \pm 0.05$ and $0.74 \pm 0.03$. The discrepancies in val-
\end{abstract}

Correspondence to: J. C. Barnard (james.barnard@pnl.gov) ues of $\varpi_{0}$ simulated by the full WRF-Chem model thus cannot be attributed to the "aerosol chemistry to optics" module. The discrepancy is more likely due, in part, to poor characterization of emissions near the T1 site, particularly black carbon emissions.

\section{Introduction}

Radiative aerosol forcing of climate is an area of active study with important implications for climate predictions. These predictions are often provided by global climate models, which in turn rely on parameterizations of the myriad complex physical processes of the climate system. An important step in developing and implementing these parameterizations is the testing of aerosol modules prior to implementation in global climate models. Most of these modules can be categorized as either chemical transport modules (CTM), which calculate the aerosol mass concentrations in space and time, or radiative transfer modules (RTM), which relate aerosol mass to aerosol optical properties and calculate radiative forcing. The evaluation of these modules often uses measurement-model "check points", as described in Bates et al. (2006); for example, one such check point could be the comparison of aerosol mass measurements with computations of the same obtained from a CTM. If the requisite data are available, the string of calculations that begins with aerosol formation and concludes with radiative forcing can be evaluated at each check point. This approach has the potential to isolate shortcomings in each module or to identify problems with input to the modules, such as emissions.

We adopt a similar approach to evaluate the performance of one aerosol module that computes aerosol optical properties from aerosol chemical properties. The specific module

Published by Copernicus Publications on behalf of the European Geosciences Union. 
under scrutiny is part of the chemistry version of the Weather Research and Forecasting model, known as WRF-Chem (Fast et al., 2006; Grell et al., 2005). As noted by Ghan and Schwartz (2007), regional models provide an important test bed for evaluating aerosol process modules, and WRFChem represents a well-known example of a regional model being used in this fashion (Fast et al., 2009). Specifically, our evaluation is performed by comparing the module's simulations of single scattering albedo, $\varpi_{0}$, scattering coefficient, $B_{\text {scat }}$, and absorption coefficient, $B_{\text {abs }}$, to field measurements of these optical properties obtained as part of the MILAGRO field campaign that took place in March 2006 in the Mexico City Metropolitan Area (MCMA). These measurements, as well as the WRF-Chem module, are described below. Evaluation of this module is particularly important because the aerosol optical properties calculated by the module serve as input to other WRF-Chem modules that calculate photolysis rates, such as FAST-J (Barnard et al., 2004; Wild et al., 2000), and shortwave radiative fluxes (Goddard scheme, Chou et al., 1998). Other WRF-Chem modules pertaining to aerosol chemistry have been evaluated by performing idealized box-model studies (e.g. Zaveri et al., 1999, 2008) before their inclusion in WRF-Chem. WRFChem has also been evaluated against numerous field campaign measurements, including the International Consortium for Atmospheric Research on Transport and Transformation (ICARTT)/New England Air Quality Study (NEAQS) (Gustafson et al., 2007; Chapman et al., 2009; McKeen et al. 2007), the MILAGRO field campaigns (Fast et al., 2009; Tie et al. 2009), and the Texas Air Quality (TexAQS) 2000 and 2006 field studies (Fast et al., 2006; McKeen et al., 2009; Wilczak et al. 2009). Fast et al. (2009) describe the WRFChem configuration used for MILAGRO as well as the emission inventories.

The particular motivation for the evaluation of WRFChem's optical module is illustrated in Fig. 1, which shows a comparison of a full WRF-Chem simulation of the finemode $\varpi_{0}$ (the solid red line) with observations of $\varpi_{0}$ (the solid blue line) obtained from measurements of $B_{\text {scat }}$ and $B_{\text {abs }}$ made at the T1 site of the MILAGRO campaign (Doran et al., 2007a, b). The T1 site is located at a latitude of $19^{\circ} 43^{\prime} \mathrm{N}$, a longitude of $98^{\circ} 08^{\prime} \mathrm{W}$, and at an altitude of 2340 $\mathrm{m})$. The wavelength of both the simulations and observations is $870 \mathrm{~nm}$. The measurements in Fig. 1 show a distinct diurnal variation in $\varpi_{0}$ that is missing in the simulation; additionally, the simulation seriously overestimates the average value of $\varpi_{0}(0.87$ and 0.78 for the calculated and observed values, respectively). There are numerous potential sources of these discrepancies, e.g., poor characterization of emissions, problems with the CTM and/or RTM components of WRF-Chem, etc. An evaluation of the "chemistry to optical properties" module can help narrow the range of possibilities.

We note that our evaluation will test the module "as is", i.e., we do not attempt to improve the module's performance

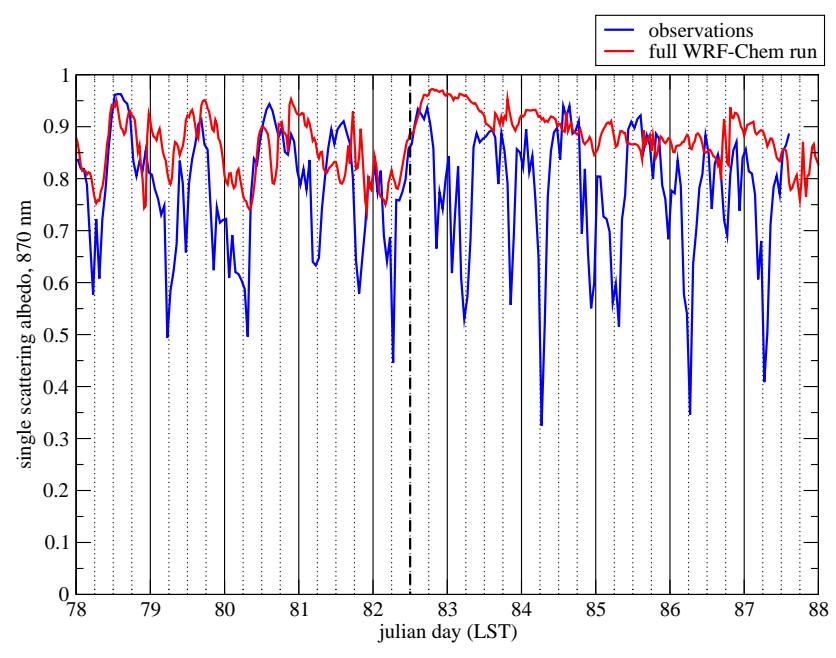

Fig. 1. The solid red line shows the single scattering albedo as calculated by the WRF-Chem model with full prognostic chemistry. The solid blue line represents the observations. (For convenience, we note that day 78 corresponds to 19 March 2006.)

by adjusting the module's internal parameters. (Such internal parameters include, for example, the densities assigned to the chemical species.) However, we will briefly evaluate how uncertainties in these parameters affect the final outcome. In this regard our evaluation borrows some features from those found in more formal closure studies (Quinn et al., 1996), where the scrutiny of the uncertainties is vital in determining whether closure, defined as agreement between the calculated and measured properties within experimental uncertainties, is achieved.

\section{The WRF-Chem module, input data, and optical data}

\subsection{WRF-Chem "aerosol chemistry to aerosol optical properties" module}

The WRF-Chem "aerosol chemistry to aerosol optical properties" module is based on a sectional approach, because this approach conveniently connects the WRF-Chem chemical module, MOSAIC (Zaveri et al., 2008) to the optical properties module. (From henceforth, unless otherwise mentioned, "module" refers specifically to WRF-Chem's aerosol "chemical properties to optical properties" module.) The size bins are based on dry physical diameter, $D_{p}$, with bin widths that increase geometrically. The first bin extends from a lower limit of $0.0390625 \mu \mathrm{m}$ to an upper limit of $0.078125 \mu \mathrm{m}$. These limits increase by powers of two, up to the largest bin, that contains particles that lie in the range, $5 \mu \mathrm{m}<D_{p}<10 \mu \mathrm{m}$. In each bin, the particles are assumed to be spherical and internally mixed. The use of size bins, spherical particles, and internal mixing are significant simplifications; ideally we would like to compute aerosol optical 
properties knowing the chemical composition at every point within an individual aerosol particle of arbitrary size and shape. Single particle approaches are now available for spherical particles (Zaveri et al., 2010; Riemer et al., 2009), but are far too computationally demanding for use in regional scale three-dimensional models, such as WRF-Chem, or in global climate models.

Given the simplifications discussed above, the conversion from chemical to optical properties follows these steps, listed along with simplifying assumptions, as needed:

1. Chemical masses, $M_{i, j}$, with units $\mathrm{g} /\left(\mathrm{cm}^{3}\right.$ dry air $)$, and particle number, $N_{i}$, with units \#/(kg dry air), are computed for each bin by MOSAIC, where the subscript " $i$ " denotes bin number (1 through 8 ) and " $j$ " the chemical species. Eleven chemical species are considered, which include black carbon (BC), organic mass (OM), water, and various ionic species, such as sulfate and nitrate.

2. For each bin " $i$ " the masses are converted to volumes, $V_{i, j}$, with units $\mathrm{cm}^{3} /\left(\mathrm{cm}^{3}\right.$ dry air $)$, by dividing by the density of each chemical species, $\rho_{i}$, so that $V_{i, j}=$ $M_{i, j} / \rho_{i}$. The assumed densities are given in Table 1 .

3. The physical diameter assigned to each bin, $D_{p, i}$, is found by summing over all $V_{i, j}$ in a bin, assuming spherical particles, so that $D_{p, i}=2\left(\left(\sum_{j=1}^{11} V_{i, j} / N_{i}\right) / \frac{4}{3} \pi\right)^{1 / 3}$. The aerosol size distribution is therefore defined by $N_{i}$ and associated $D_{p, i}$ for each bin.

4. Now that the size distribution is defined, the module calculates the bulk refractive index of the particles in a bin. For this process, we must chose a refractive index mixing rule; these rules have been described in Bond et al. (2006), and references therein. We chose the spherical shell/core configuration, where all species except $\mathrm{BC}$ are uniformly distributed within a shell that surrounds a core consisting only of BC. This configuration was selected because as noted in Bond et al., it avoids the artificial absorption enhancement of $\mathrm{BC}$ that comes with volume mixing rules, which assume the $\mathrm{BC}$ is uniformly distributed throughout the particle. We denote $m_{s, i}$ and $m_{c, i}$ as the bulk complex refractive indices of the shell and core, respectively, for the bin " $i$ ", and let $m_{j}$ be the refractive index of each of the chemical constituents " $j$ ". Then the shell refractive index is given by

$$
m_{s, i}=\frac{\sum_{\substack{j=1 \\ j \neq B C}}^{11} m_{j} V_{i, j}}{\sum_{\substack{j=1 \\ j \neq B C}}^{11} V_{i, j}}
$$

and the core refractive index is assigned the value of $1.85+\mathrm{i} 0.71$. This value is the midpoint of a range of values thought plausible as presented by Bond and Bergstrom (2006), specified at $550 \mathrm{~nm}$. We note here, however, that Bond and Bergstrom state that this refractive index may be assumed to be constant across the visible spectral region, extending from $400 \mathrm{~nm}$ to $700 \mathrm{~nm}$, but it may be much different at ultraviolet and infrared wavelengths. The refractive indices for the shell components are also listed in Table 1.

Shell/core Mie theory (Ackerman and Toon, 1981) is then used to find the absorption efficiency, $Q_{a, i}$, the scattering efficiency $Q_{s, i}$, and the asymmetry parameter, $g_{i}$, for each bin. The optical properties at $870 \mathrm{~nm}$ are found in the usual manner by summing over the size distribution:

$$
\begin{aligned}
& B_{\text {scat }}=\sum_{i=1}^{8 \text { bins }} N_{i} Q_{s, i} \pi\left(\frac{D_{p, i}}{2}\right)^{2} \\
& B_{\text {abs }}=\sum_{i=1}^{8 \text { bins }} N_{i} Q_{a, i} \pi\left(\frac{D_{p, i}}{2}\right)^{2} \\
& g=\frac{\sum_{i=1}^{8 \text { bins }} N_{i} Q_{s, i} \pi\left(\frac{D_{p, i}}{2}\right)^{2} g_{i}}{\sum_{i=1}^{\text {8bins }} N_{i} Q_{s, i} \pi\left(\frac{D_{p, i}}{2}\right)^{2}} \\
& \varpi_{0}=\frac{B_{\text {scat }}}{B_{\text {scat }}+B_{\text {abs }}}
\end{aligned}
$$

where $g$ is the overall asymmetry parameter.

For the purposes of module testing, the above scheme remains intact, except that measured size distributions and chemical masses are substituted for modeled quantities $\left(M_{i, j}, N_{i}\right)$ in step one. These measurements are described below.

\subsection{Aerosol chemical measurements}

Aerosol chemical measurements included elemental carbon (EC), aerosol organic carbon (OC) and concomitant OM content, and ionic species. The total mass of aerosols with aerodynamic diameters less than $2.5 \mu \mathrm{m}$ (called $\mathrm{PM}_{2.5}$ aerosols or $\mathrm{PM}_{2.5}$ mass) was also measured at the T1 site. Elemental carbon and BC are operationally defined (Pöschl, 2003), but for this paper we take $\mathrm{EC}$ and $\mathrm{BC}$ to be interchangeable. These mass measurements, including the $\mathrm{PM}_{2.5}$ measurement, are used to estimate the fine mode dust content of the aerosol, as will be explained below. 
Table 1. Assumed densities and refractive indices $(n+\mathrm{i} k)$ of the indicated species. Unless otherwise noted, the refractive indices are for a wavelength of $870 \mathrm{~nm}$.

\begin{tabular}{lccc}
\hline species & Density $\left(\mathrm{g} / \mathrm{cm}^{3}\right)$ & Refractive index (real), $n$ & Refractive index (imaginary), $k$ \\
\hline $\mathrm{SO}_{4}$ & 1.8 & 1.52 & 0 \\
$\mathrm{NO}_{3}$ & 1.8 & 1.5 & 0 \\
$\mathrm{NH}_{4}$ & 1.8 & 1.5 & 0 \\
$\mathrm{Cl}$ & 2.2 & 1.45 & 0 \\
$\mathrm{Na}$ & 2.2 & 1.45 & 0 \\
$\mathrm{Ca}$ & 2.6 & 1.56 & 0 \\
$\mathrm{Mg}$ & 1.8 & 1.5 & 0 \\
Organic Matter (OM) (Kanakidou et al., 2005; re- & 1.4 & 1.45 & 0 \\
fractive index range is 300 nm to 800 nm) & & 1.85 & 0.71 \\
Elemental Carbon (EC) (Bond and Bergstrom, & 1.8 & 1.55 & 0.002 \\
2006; refractive index for 550 nm) & & \\
Dust (Prasad and Singh, 2007; Mishra and Tri- & 2.6 & 1.33 & 0.0 \\
pathi, 2008) & & & \\
water & 1.0 & & \\
\hline
\end{tabular}

A Sunset Labs OCEC instrument (Birch and Cary, 1996; Doran et al., 2007a, b), using a thermo-optical technique, provided measurements of OC and EC for $\mathrm{PM}_{2.5}$ aerosols. The estimate error of these measurements is $\pm 0.2 \mu \mathrm{g} / \mathrm{m}^{3}$. The organic carbon concentration was converted to OM concentration by multiplying by the factor 1.7 (Aiken et al., 2008), so that $\mathrm{OM}=1.7$ OC. Inorganic ionic species (e.g., $\mathrm{Na}^{+}, \mathrm{K}^{+}, \mathrm{Ca}^{2+}, \mathrm{Mg}^{2+}, \mathrm{Cl}^{-}, \mathrm{NO}_{3}^{-}, \mathrm{NO}_{2}^{-}, \mathrm{SO}_{4}^{2-}$ ) were measured with a Particle into Liquid Sampler (PILS) instrument (Orsini et al., 2003; Weber et al., 2001), also for $\mathrm{PM}_{2.5}$ aerosols. The PILS uses a small amount of water vapor to form water droplets around individual aerosol particles, dissolving water soluble components. The water is collected and analyzed using ion chromatography. This analysis cycle takes about four minutes, thereby producing a semicontinuous time series of aerosol inorganic ionic species. The uncertainty of these measurements is stated as $\pm 10 \%$ (Weber et al., 2001).

$\mathrm{PM}_{2.5}$ at the $\mathrm{T} 1$ site was measured with a tapered element oscillating microbalance (TEOM) instrument, with an estimated uncertainty of $\pm 5 \%$. Figure 2 shows the various mass measurements averaged over the diurnal cycle, in a manner similar to chemical mass measurements presented by Paredes-Miranda et al. (2009) for the MILAGRO T0 site. The procedure averages all the measurements that fall in the time bin delineated by a lower limit of 00:00 LST and an upper limit of 01:00 LST, producing an average value for this hour, and so on for the other $23 \mathrm{~h}$ of the day. The display of diurnal averages aids in explaining the variation of aerosol optical properties. These averages are found over a time period extending from day 78 (19 March 2006) through most of day 87 (28 March 2006). Fast et al. (2007) subdivide the meteorology during the MILAGRO campaign into three regimes, and our data span two of these regimes. We seg- regate the data into one or the other meteorological period; the upper panel shows data for conditions that were mostly clear (19 March 2006 through 23 March 2006, 12:00 LST), while the lower panel is for the regime during which precipitation occurred (23 March 2006, 12:00 LST through 29 March 2006). For convenience, we refer to these two regimes as "clear" and "showery", respectively. To better show the concentrations of the various species, two graphs are used for each time period. One graph shows $\mathrm{PM}_{2.5}$ mass, $\mathrm{OM}$, and "fine mode dust", while the other graphs shows various inorganic species $\left(\mathrm{SO}_{4}, \mathrm{NO}_{3}, \mathrm{NH}_{4}, \mathrm{Cl}\right)$, crustal materials $(\mathrm{Na}$, $\mathrm{Ca}, \mathrm{Mg}$ ), and $\mathrm{EC}$. The fine mode dust is found by subtracting all known substances (EC, OM, and inorganics) from the $\mathrm{PM}_{2.5}$ mass and assuming that this residual is dust. Support for this assumption is found by noting that: (1) the residual is substantially reduced during the showery period, consistent with reduced dust emissions occurring during the wet surface conditions; and (2) a considerable amount of dust was often observed at the T1 site (Querol et al., 2008).

For our analysis we treated the aerosols at the surface as dry. The assumption of a dry aerosol is supported by the work of Moffet et al. (2008a, b), who used single particle mass spectrometry (an aerosol time-of-flight mass spectrometer, ATOFMS) to analyze aerosol chemical and radiative properties, and noted that the radiative microphysical properties displayed no detectable RH dependence, thus indicating dry particles. This is broadly consistent with the measurements of relative humidity (RH) during the MILAGRO campaign, e.g., as reported by Doran et al. (2007a) for the T2 site. They found daytime RH values ranging between $10 \%$ and $40 \%$ during the clear period, although higher values were found at night and for parts of some days during the showery period. 

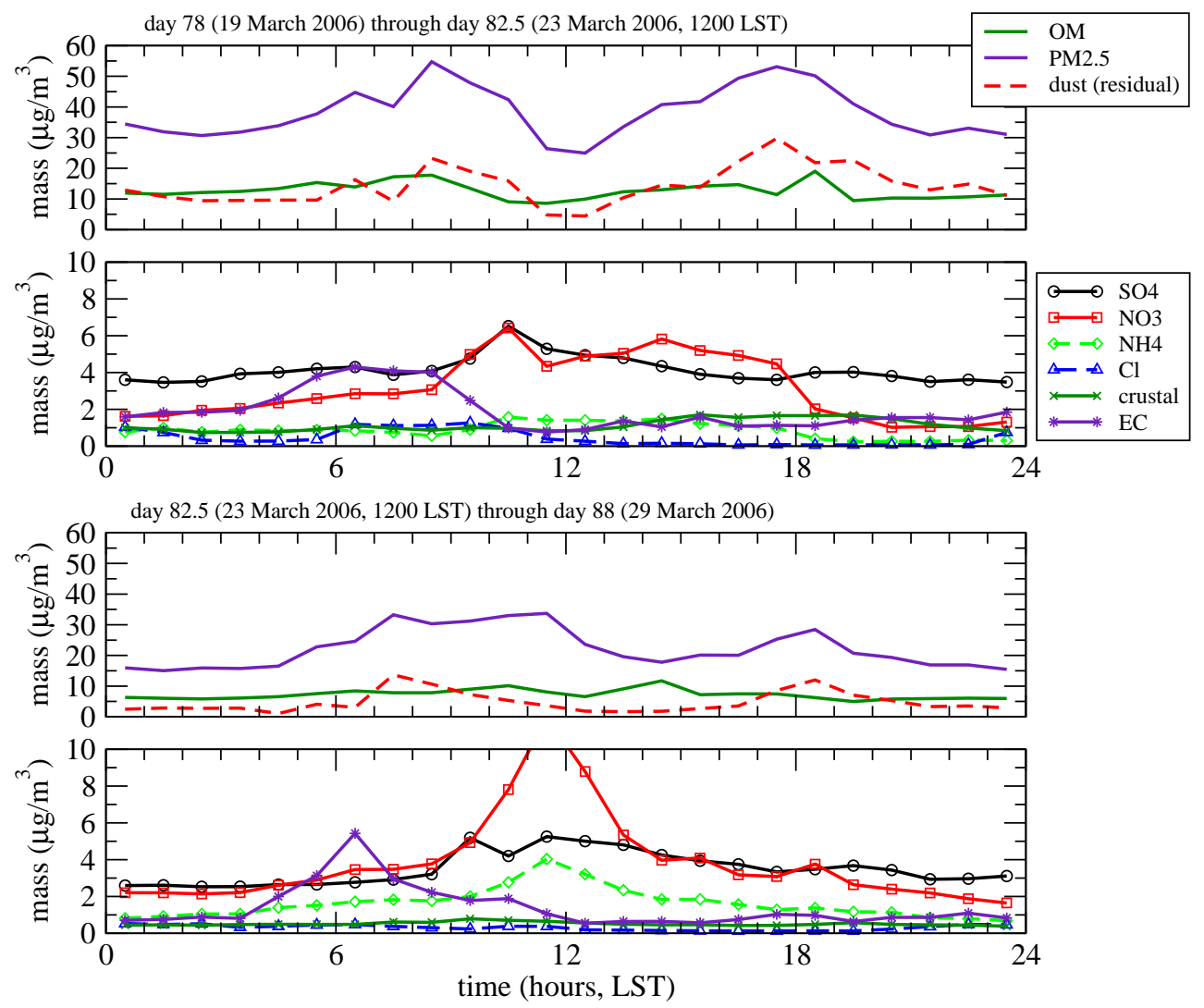

Fig. 2. Diurnally averaged times series of chemical species and $\mathrm{PM}_{2.5}$ mass. The two upper panels show these constituents during the clear period of little precipitation, while the two lower panels show the same constituents during the showery period. For clarity, the mass measurements are broken down into two plots: $\mathrm{OM}, \mathrm{PM}_{2.5}$, and dust compose one plot, while $\mathrm{SO}_{4}, \mathrm{NO}_{3}, \mathrm{NH}_{4}, \mathrm{Cl}_{\text {, crustal materials, and }}$ EC compose the second plot. Note that $\mathrm{PM}_{2.5}$ mass is significantly lower during the showery period.

We make a few remarks regarding the time variation of the chemical species. First, over the course of the campaign, the mass concentrations are larger during the clear period than the showery period, most likely an effect of precipitation scavenging during the showery period. Second, total mass $\left(\mathrm{PM}_{2.5}\right)$ shows a diurnal trend, with two maxima, one occurring at about 09:00 LST and the other at about 18:00 LST. The first peak results from emissions trapped in the morning stable boundary layer. After about 09:00 LST a convective boundary layer develops, resulting in significant reductions in surface mass concentrations. The secondary peak in $\mathrm{PM}_{2.5}$ at 18:00 LST is probably caused by windblown dust. The broad plateau in the inorganic species $\mathrm{NO}_{3}$ and $\mathrm{NH}_{4}$ that occurs between 10:00 LST and 18:00 LST (clear sky period), could be caused by the formation of new secondary inorganic aerosol, as well as residual mass carried over from the previous day. This process was also thought to occur at the T0 site (Paredes-Miranda et al., 2009). Although we cannot identify the cause of these peaks, the spikes in $\mathrm{NH}_{4}$ and $\mathrm{NO}_{3}$ concentrations that appear around noon for the showery period appear to be real, and are seen in the data on three consecutive days, 27 March through 29 March.

\subsection{Optical measurements}

Optical measurements were made at the MILAGRO T1 site using a photoacoustic spectrometer (PAS), as described in Arnott et al. (1999). This instrument uses sound pressure produced by light absorption in an acoustic resonator to measure aerosol absorption. To find $\varpi_{0}$, scattering measurements are required, and these also are obtained from the PAS, using reciprocal nephelometry (Rahmah et al., 2006). The use of this particular combination of measurements to find $\varpi_{0}$ is described in Paredes-Miranda et al. (2009). At the T1 site, the PAS measurements were made at only one wavelength, $\lambda$, of $870 \mathrm{~nm}$. For this study, focusing on $\varpi_{0}$ at this wavelength is advantageous because we avoid the possibly major complications of dust absorption (Sokolik and Toon, 1999), and organic carbon absorption, which may become significant at wavelengths less than about $600 \mathrm{~nm}$ (Bergstrom et al., 2010; Barnard et al., 2008; and references therein). We rely solely on PAS absorption measurements, because these measurements are made without filter substrates. Recent evidence (Lack et al., 2008; Subramanian et al., 2007) suggests that filter-based measurements of absorption, made 
in the presence of large amounts of organic carbon, could be highly suspect because of soiling of the filter by the organic component of the aerosol.

Average absorption values were obtained every two minutes and were subsequently averaged over one hour intervals; the 1-h averages are used in this study. Calibration and use of the PAS is described in Lewis et al. (2008), Sheridan et al. (2005), and Arnott et al. (2000). Their experience has led to estimates of the uncertainties in absorption and scattering measurements at the $\mathrm{T} 1$ site of $10 \%$ and $15 \%$, respectively. These are estimates of systematic error (as opposed to random error) and are not reduced by averaging (ParedesMiranda et al., 2009). If we assume that these errors work in concert to maximize the error in $\varpi_{0}$ then the uncertainty in the inferred values of $\varpi_{0}$ would be about $6 \%$.

If the particles are large, the magnitude of the scattering measurements will always be less than the true scattering because of difficulties in measuring the forward scattering peak, which becomes significantly more prominent as the particle size increases. However, optical properties of very large particles, with aerodynamic diameters, $D_{a}$, greater than about 2 to $3 \mu \mathrm{m}$, were not measured by the PAS because of line and inlet losses that reduced the sampling efficiency of large particles to virtually zero. We thus assume that the largest particles that were measured did not exceed $2.5 \mu \mathrm{m}$, consistent with $\mathrm{PM}_{2.5}$ measurements. In terms of physical diameter, this cut-off is about $1.9 \mu \mathrm{m}$, found using the well-known relationship between physical and aerodynamic diameter for spherical particles, $D_{p}=D_{a} / \sqrt{\rho_{\text {aer }}}$ (e.g., Shaw et al., 2007), where $\rho_{\text {aer }}$ is the density of the aerosol, taken to be 1.8 $\mathrm{g} / \mathrm{cm}^{3}$. Because coarse mode particles could not be measured, our $\varpi_{0}$ values should be considered as "fine mode" values.

\subsection{Size distribution}

Aerosol size distributions were measured at the surface using a scanning mobility particle sizer (SMPS; this instrument is a TSI Model 3936 teamed with a TSI Model 3081 differential mobility analyzer and a 3025A condensation particle counter; http://www.tsi.com). As configured during the MILAGRO campaign, this instrument sized particles between 0.014 and $0.74 \mu \mathrm{m}$ in electric mobility diameter. As noted by DeCarlo et al. (2004), the electric mobility diameter is equivalent to the physical diameter for spherical particles. Because the upper limit of the size distribution measurements is too small to capture the larger particles sensed by the PAS and chemical measurement equipment, it is necessary to extrapolate the SMPS measurement to larger diameters.

Figure 3 illustrates this process. The upper panel shows a typical size distribution (the blue dots) measured during the clear period, while the lower panel shows a similar size distribution taken during the showery period. The two distributions differ in shape for particles larger than about $0.5 \mu \mathrm{m}$, at which point the size distribution increases for larger par-
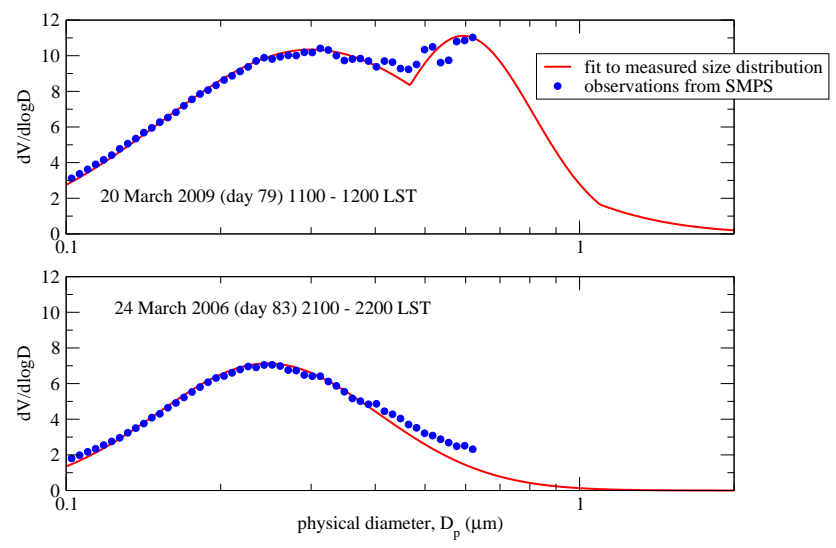

Fig. 3. The blue dots represent the measured size distribution, as measured by the SMPS. The size distribution is an hourly average. The red curves show fits to these data.

ticles during the clear period and decreases for the showery period. These characteristic shapes were fairly consistent for all the hourly averaged size distributions in each respective period. The presence of larger particles for the clear period could be due to windblown dust, which was presumably being suppressed by rainfall during the showery period.

For the showery times, we found that a log-normal function fit the size distribution quite well, and we used this function to extrapolate the distribution to sizes larger than $0.74 \mu \mathrm{m}$. The fit distribution is shown by the red line. For the clear periods, we used two log-normal distributions, once of which was fit to particles less than $0.5 \mu \mathrm{m}$ in diameter, and the other to the larger sizes. This combined distribution is also shown in Fig. 3. For both the clear and showery periods, both distributions tend to zero as the size increases, thereby simulating, perhaps crudely, the sampling inefficiencies of the chemical and optical instruments. The credibility of these extrapolated size distributions is bolstered by comparing total aerosol volume derived from them with the volume estimates, $V_{i, j}$, obtained from the aerosol mass measurements (e.g., see Sect. 2.1). The $V_{i, j}$ are summed over all bins " $i$ " and all chemical constituents " $j$ " to yield total aerosol volume, $V_{m}$, where the subscript " $m$ " denotes that the volume has been derived from the mass measurements. For this procedure we use hourly averaged values. By integration of the hourly averaged size SMPS distributions for all $D_{p}<2.0 \mu \mathrm{m}$, we obtain another measure of the aerosol volume denoted $V_{s}$. Figure 4 shows a comparison of the two volumes, segregated by time into "clear" (black dots) and "showery" (red dots) periods. Given the approximations involved, the correlation is satisfactory. We note in passing that during the showery period, when aerosol mass is generally reduced, both volumes are generally smaller than during the clear period, as would be expected. 


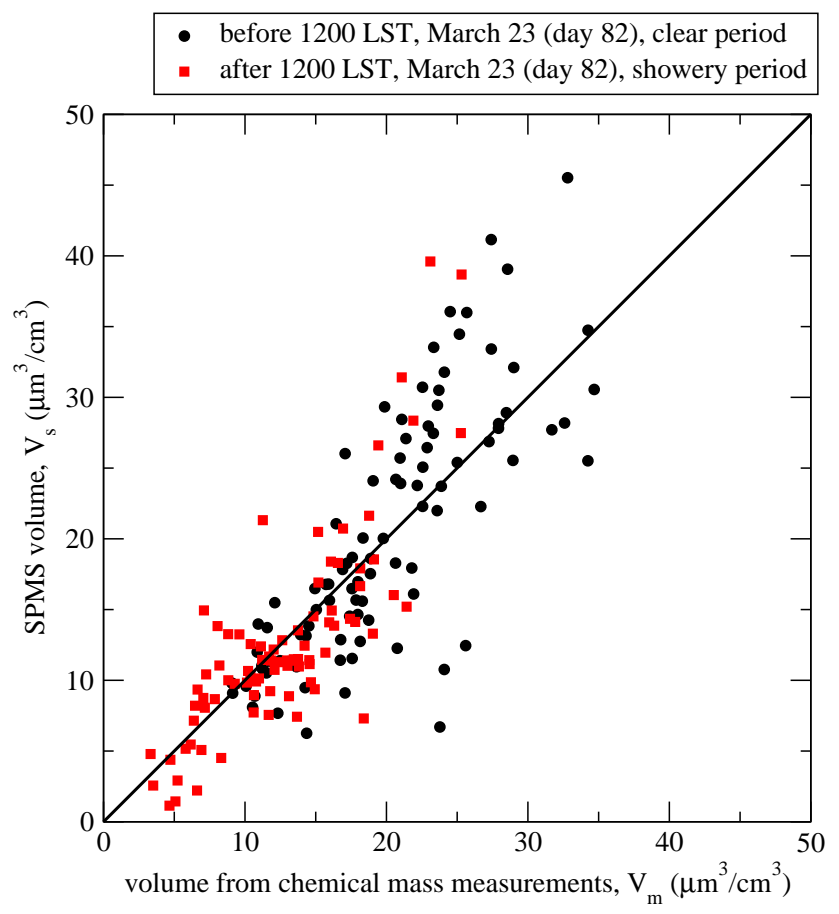

Fig. 4. Scatterplot of aerosol volumes derived from the chemical mass measurements, or the size distribution measurements (and extrapolation, see text).

\section{Methodology and results}

\subsection{Results}

Given the measured size distribution, and the measured chemical properties, the WRF-Chem module calculates aerosol optical properties. Each bin of the module is "filled" by assuming that the mass fraction of the chemical constituents in each bin is the same across all bins. The number of particles associated with each bin is obtained by integrating the observed size distribution between the bin limits. Because the assumed size distributions do not extend much beyond a diameter of about $2 \mu \mathrm{m}$, the two upper size bins in the module do not contain any aerosol mass. Once the size bins are filled, the calculation proceeds as described in Sect. 2.1. The calculations are performed using hourly averaged data, and accordingly, the aerosol optical properties are calculated every hour that data are available.

Aerosol radiative transfer calculations require aerosol optical properties that characterize extinction, absorption, and the phase function. The extinction is the sum of the scattering and absorption, and we examine these two components first. Figure 5 shows time series of calculated and observed $B_{\text {abs }}$ (upper panel) values and $B_{\text {scat }}$ (lower panel). The dashed vertical line in these plots separates the clear (left) from the showery (right) period. The hourly calculated values are indicated by the red dots connected by a red dashed line, and observed values are shown by the blue line. We note that there are several time periods with missing size distribution and/or chemical mass data, and for these periods no calculations are possible. One long stretch occurs from the end of day 84 (25 March 2006) though most of day 85.

Focusing first on $B_{\mathrm{abs}}$, the calculated and observed $B_{\mathrm{abs}}$ values exhibit similar diurnal patterns, with a large peak occurring between 06:00 and 08:00 LST and much smaller values at other times. These diurnal maxima correlate well with the diurnal maxima in $\mathrm{BC}$ concentration seen in Fig. 2, suggesting that fluctuating $\mathrm{BC}$ concentrations control most of the absorption at $870 \mathrm{~nm}$. Small absorption contributions by dust and $\mathrm{OM}$ are possible, but the absorption signal of these components is probably too small to detect at $870 \mathrm{~nm}$. Overall, the module exhibits reasonable skill in predicting $B_{\text {abs, }}$, but has a tendency to overestimate the observed values. The regression line between simulations and observations is $B_{\text {abs,calculated }}=-1.3 \mathrm{Mm}^{-1}+1.34 \cdot B_{\text {abs, observed }}$ with a correlation coefficient $\left(r^{2}\right)$ of 0.82 . When averaged over the entire comparison period, the calculated and observed values of $B_{\text {abs }}$ are $11.7 \mathrm{Mm}^{-1}$ and $9.7 \mathrm{Mm}^{-1}$, respectively.

For $B_{\text {scat }}$, we see that the agreement between calculated and observed values is more problematic; the regression line is $B_{\text {scat,calculated }}=14.8 \mathrm{Mm}^{-1}+0.46 \cdot B_{\text {scat, observed }}$ with a $r^{2}=0.16$. The module does calculate larger $B_{\text {scat }}$ values during the clear period and smaller values during the showery time, consistent with the optical data and with the decreased aerosol volume during the showery period (Fig. 3), but there is a tendency for the calculated peaks to occur a few hours before the observed ones, especially during the clear period. Interestingly, when averaged over the entire comparison periods, the calculated and observed values are remarkably similar, $30.4 \mathrm{Mm}^{-1}$ and $34.1 \mathrm{Mm}^{-1}$, respectively. We will discuss the uncertainty of these values below. The averaged extinction coefficient, $B_{\text {ext }}$, is the sum of the averages of $B_{\text {scat }}$ and $B_{\mathrm{abs}}$, or $42.1 \mathrm{Mm}^{-1}$ and $43.8 \mathrm{Mm}^{-1}$, for calculated and observed values, respectively.

Figure 6 shows time series of calculated and observed $\varpi_{0}$ values (Eq. 2) at $870 \mathrm{~nm}$. A distinct diurnal pattern is evident in the observed time series for $\varpi_{0}$. During the course of a day, $\varpi_{0}$ has a pronounced minimum at about 06:00 LST and a broad maximum around 15:00 LST. We see that despite the difficulty the module has in predicting the daily pattern of $B_{\text {scat }}$, the diurnal behavior of the observations is approximately captured by the calculations of $\varpi_{0}$. The correlation $\left(r^{2}\right)$ between observed and calculated values is 0.56 ; with an associated regression line of $\varpi_{0 \text {,calculated }}=0.13+$

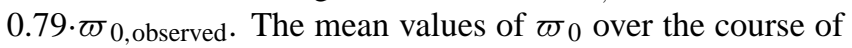
the comparison period are 0.74 and 0.78 , for the calculated and observed values, respectively.

For the MILAGRO T1 site, the large daily swings in $B_{\mathrm{abs}}$ govern the diurnal behavior of the $\varpi_{0}$, in part because $\varpi_{0}$ values are more sensitive to changes in $B_{\text {abs }}$ than $B_{\text {scat }}$. (By considering $\partial \varpi_{0} / \partial B_{\text {scat }}$ and $\partial \varpi_{0} / \partial B_{\text {abs }}$, and using typical values for $B_{\text {abs }}, B_{\text {scat }}$, and $\varpi_{0}$, we find that $\varpi_{0}$ is three times 

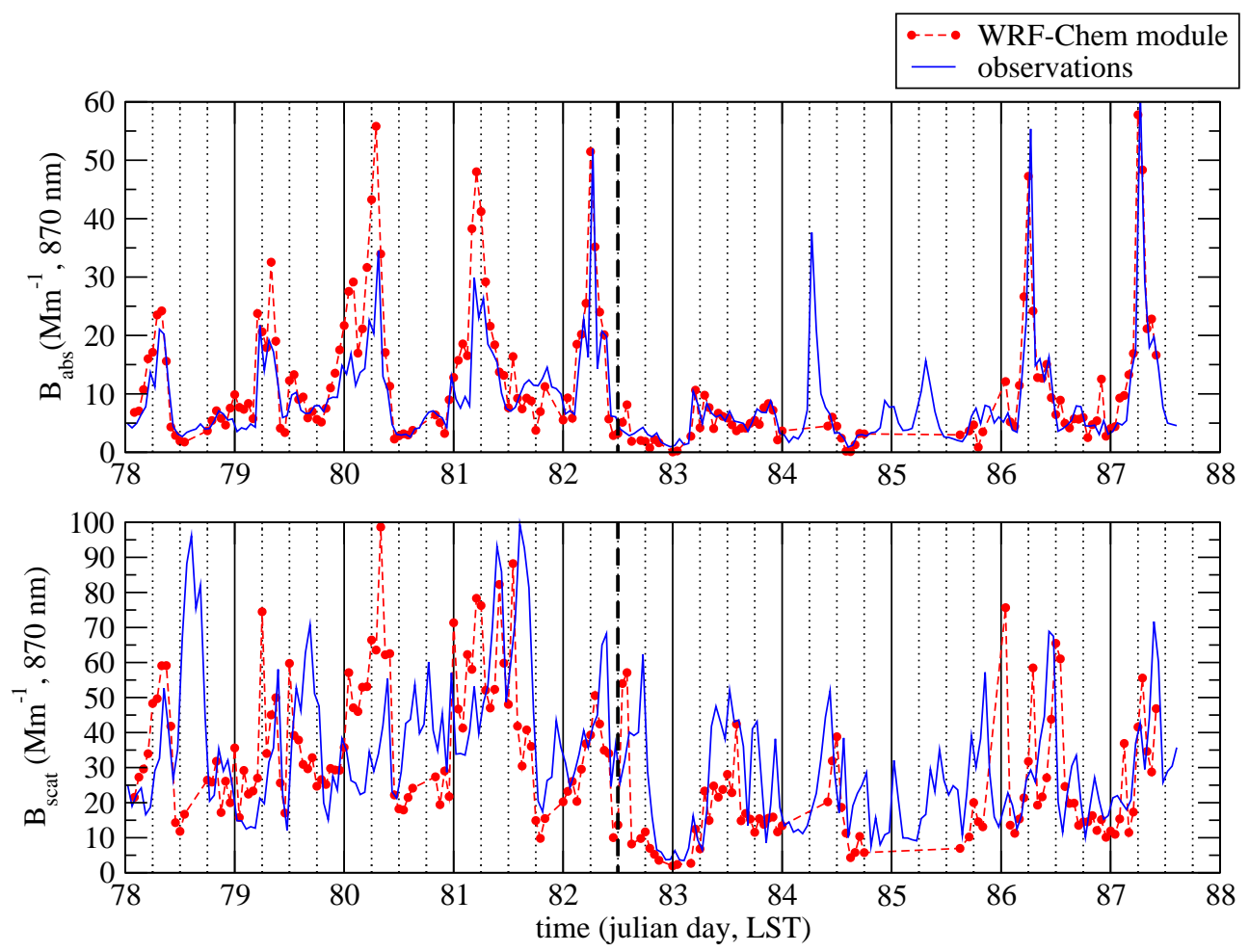

Fig. 5. The top panel shows the absorption coefficient, $B_{\text {abs }}$, while the bottom panel shows the scattering coefficient, $B_{\text {scat }}$. The blue lines indicate the observations, while the red dots show simulations of these coefficients derived from the WRF-Chem "chemical to optical properties" module. Hourly averages are shown. The dashed red line that connects the dots aids in the comparison between the simulations and observations. Note that there are significant time periods when missing data prevented a simulation from taking place; for example, the time span from the end of day 84 continuing on through most of day 85. We again note for convenience that day 78 is 19 March 2006 . The vertical, bold dashed line that occurs at time 82.5 separates the clear (julian day $<82.5$ ) and showery (julian day $\geq 82.5$ ) periods.

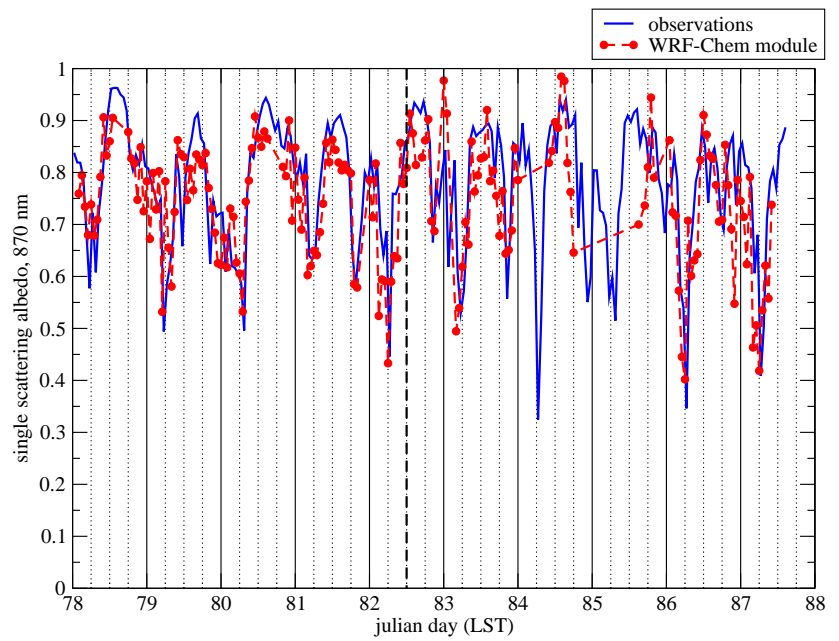

Fig. 6. Same as Fig. 5, except for single scattering albedo.

more sensitive to changes in $B_{\text {abs }}$ than $B_{\text {scat }}$. This sensitivity of $\varpi_{0}$ to $B_{\text {abs }}$ is further amplified by the large swings in $B_{\text {abs }}$ that occur in the morning when $B_{\text {scat }}$ is relatively small).
The module performance depicted in Fig. 6 shows a distinct improvement over the full WRF-Chem simulation in Fig. 1. This implies that most of the discrepancy in that figure cannot be attributed to the module evaluated here.

Over the entire comparison period the averaged $\varpi_{0}$ for the calculations and observations are 0.74 and 0.78 , respectively. Marley et al. (2009) report a mean observed value of $\varpi_{0}$ at $550 \mathrm{~nm}$ of 0.68 at the T1 site and a diurnal pattern similar to that reported here (Figure 1), over a time period extending from 1 March 2006 through 29 March 2006 (e.g., see Figure 3 in Marley et al.). This value is lower than that measured at $870 \mathrm{~nm}$, suggesting enhanced absorption at the lower wavelengths, perhaps attributable to dust (Bergstrom et al., 2010; Bergstrom et al., 2007) or organic carbon (Bergstrom et al., 2010; Barnard et al., 2008; Kirchstetter et al. 2004).

For the sake of comparison, it is interesting to show the aerosol optical properties for the full, prognostic WRF-Chem run. These are shown in the fourth column of Table 2. The single scattering albedo, for the full 10-day period, is 0.87 , as noted above. The prognostic WRF-Chem simulation substantially underpredicts $B_{\text {abs }}$ for all time periods, and overpredicts $B_{\text {scat }}$ for the full time period as well as for the showery period. For the clear period, both observed and 
Table 2. Mean values of observed and calculated aerosol optical properties for the period 19 March through 28 March 2006. The calculated properties are shown for the module only, as well as the full, prognostic WRF-Chem model. This table also shows comparisons for the clear and showery periods. Optical properties that do not agree within estimated uncertainties are shown in boldface. The wavelength associated with all of properties listed here is $870 \mathrm{~nm}$.

\begin{tabular}{|c|c|c|c|c|c|}
\hline Optical property & $\begin{array}{l}\text { Observations (with } \\
\text { uncertainties) }\end{array}$ & $\begin{array}{l}\text { WRF-Chem module } \\
\text { (with uncertainties) }\end{array}$ & $\begin{array}{l}\text { Full prognostic WRF- } \\
\text { Chem model }\end{array}$ & $\begin{array}{l}\text { Full prognostic WRF- } \\
\text { Chem with observed } \\
\text { BC }\end{array}$ & $\begin{array}{l}\text { Time } \\
\text { period }\end{array}$ \\
\hline$\varpi_{0}$ & $0.78 \pm 0.05$ & $0.74 \pm 0.03$ & 0.87 & 0.78 & Full \\
\hline$B_{\text {scat }}$ & $34.1 \pm 5.1 \mathrm{Mm}^{-1}$ & $30.4 \pm 3.4 \mathrm{Mm}^{-1}$ & $46.4 \mathrm{Mm}^{-1}$ & $46.5 \mathrm{Mm}^{-1}$ & “ \\
\hline$B_{\mathrm{abs}}$ & $9.7 \pm 1.0 \mathrm{Mm}^{-1}$ & $11.7 \pm 1.2 \mathrm{Mm}^{-1}$ & $5.6 \mathrm{Mm}^{-1}$ & $11.1 \mathrm{Mm}^{-1}$ & “ \\
\hline$\varpi_{0}$ & $0.77 \pm 0.05$ & $0.74 \pm 0.03$ & 0.85 & 0.72 & Clear \\
\hline$B_{\text {scat }}$ & $38.7 \pm 5.8 \mathrm{Mm}^{-1}$ & $38.1 \pm 4.1 \mathrm{Mm}^{-1}$ & $37.8 \mathrm{Mm}^{-1}$ & $38.0 \mathrm{Mm}^{-1}$ & “ \\
\hline$B_{\mathrm{abs}}$ & $11.2 \pm 1.1 \mathrm{Mm}^{-1}$ & $14.6 \pm 1.5 \mathrm{Mm}^{-1}$ & $5.6 \mathrm{Mm}^{-1}$ & $13.0 \mathrm{Mm}^{-1}$ & “ \\
\hline$\varpi_{0}$ & $0.79 \pm 0.05$ & $0.74 \pm 0.03$ & 0.90 & 0.86 & Showery \\
\hline$B_{\text {scat }}$ & $28.7 \pm 4.3 \mathrm{Mm}^{-1}$ & $21.2 \pm 3.5 \mathrm{Mm}^{-1}$ & $56.7 \mathrm{Mm}^{-1}$ & $56.4 \mathrm{Mm}^{-1}$ & “ \\
\hline$B_{\mathrm{abs}}$ & $8.0 \pm 0.8 \mathrm{Mm}^{-1}$ & $8.3 \pm 1.3 \mathrm{Mm}^{-1}$ & $5.5 \mathrm{Mm}^{-1}$ & $8.9 \mathrm{Mm}^{-1}$ & “ \\
\hline
\end{tabular}

Table 3. Averaged concentration of $\mathrm{PM}_{2.5}$ and BC for the periods indicated. The label "WRF-Chem" means that these are the concentrations predicted by the full, prognostic WRF-Chem model.

\begin{tabular}{lllll}
\hline Time period & $\mathrm{PM}_{2.5}$ (WRF-Chem) $\mu \mathrm{g} / \mathrm{m}^{3}$ & $\mathrm{PM}_{2.5}$ (observed) $\mu \mathrm{g} / \mathrm{m}^{3}$ & $\mathrm{BC}\left(\right.$ WRF-Chem) $\mu \mathrm{g} / \mathrm{m}^{3}$ & $\mathrm{BC}$ (observed) $\mu \mathrm{g} / \mathrm{m}^{3}$ \\
\hline all & 32.7 & 28.9 & 0.70 & 1.54 \\
clear & 25.8 & 38.3 & 0.71 & 1.98 \\
showery & 40.0 & 21.2 & 0.68 & 1.19 \\
\hline
\end{tabular}

calculated $B_{\text {scat }}$ values are about the same. We then ask, why is $B_{\text {abs }}$ so grossly underpredicted? Table 3 shows $\mathrm{PM}_{2.5}$ and $\mathrm{BC}$ concentrations, both measured and as predicted by WRFChem. A comparison of the $\mathrm{BC}$ concentrations reveals that the amount of BC found in the WRF-Chem simulation is far lower than the measurements; for example, for the full time period, the BC concentration is $0.70 \mu \mathrm{g} / \mathrm{m}^{3}$ for WRF-Chem, yet the measured value is $1.54 \mu \mathrm{g} / \mathrm{m}^{3}$. Because $\mathrm{BC}$ is a primary emission that is not altered significantly in the atmosphere, we attribute WRF-Chem's poor simulation of BC to the emissions inventory that does not contain enough BC.

This table also shows that on an overall basis, the prediction of $\mathrm{PM}_{2.5}$ is similar for WRF-Chem $\left(32.7 \mu \mathrm{g} / \mathrm{m}^{3}\right)$ and the observations $\left(28.9 \mu \mathrm{g} / \mathrm{m}^{3}\right)$, but major differences occur in the clear and showery period. During the clear period, WRF-Chem significantly underpredicts the $\mathrm{PM}_{2.5}$ mass, and the opposite is true in the showery period. We cannot yet explain this behavior. Because $\mathrm{PM}_{2.5}$ is closely related to the scattering (at $870 \mathrm{~nm}$ ), when the predicted $\mathrm{PM}_{2.5}$ is too large relative to the observations, the predicted $B_{\text {scat }}$ is similarly too large, and vice versa for the predicted $\mathrm{PM}_{2.5}$, when it is too small. For example, during the showery period, the simulated and observed $\mathrm{PM}_{2.5}$ values are $40.0 \mu \mathrm{g} / \mathrm{m}^{3}$ and
$21.2 \mu \mathrm{g} / \mathrm{m}^{3}$, respectively, while the simulated and observed $B_{\text {scat }}$ is $56.7 \mathrm{Mm}^{-1}$ and $28.7 \mathrm{Mm}^{-1}$, respectively. A doubling of $\mathrm{PM}_{2.5}$ leads to a doubling in the scattering. For the showery period, the discrepancy between predicted and observed $\mathrm{PM}_{2.5}$ significantly influences the scattering, and therefore the value of $\varpi_{0}$. If we calculate $\varpi_{0}$ using the observed $\mathrm{PM}_{2.5}$ (less scattering) in place of the WRF-Chem $\mathrm{PM}_{2.5}$ (more scattering), we find that $\varpi_{0}$ drops by about 0.09 .

To bolster the conjecture that the specified emissions of $\mathrm{BC}$ are too low, we start with the chemical concentrations as simulated by WRF-Chem. We make a single change to these concentrations: we replace the simulated BC concentration by the observed concentration of $\mathrm{BC}$. When this new input is fed to the module, the overall $\varpi_{0}$ value is now 0.78 , the same value as the observations. However, during the clear and showery periods, there remain significant differences (0.05 and 0.07) between the observed and calculated $\varpi_{0}$ values. The various optical properties as simulated by the module, using WRF-Chem predicted chemical concentrations with the predicted $\mathrm{BC}$ replaced by the measured $\mathrm{BC}$, are shown in the fifth column of Table 2. 
Table 4. SBDART inputs for three cases: (1) a "base case" that uses measured $\varpi_{0}$ and $B_{\text {ext }}$ to calculate top of atmosphere (TOA) aerosol radiative forcing, (2) a case that uses the "WRF-Chem optical module" calculated $\varpi_{0}$ in place of the measured $\varpi_{0}$, and ( 3 ) a case that uses

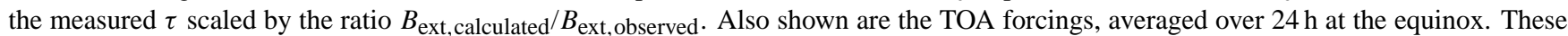
TOA forcings are listed in the last row. The spectral surface albedo is from Coddington et al. (2008). The parameters that are changed from the base case are in boldface type.

\begin{tabular}{llll}
\hline Parameters/forcing & base case (measured $\varpi_{0}$ and $\left.B_{\text {ext }}\right)$ & WRF-Chem module calculated $\varpi_{0} \begin{array}{l}\tau \text { scaled by } \\
\left(B_{\text {ext,calculated }}\right) / \\
\left(B_{\text {ext, observed }}\right)\end{array}$ \\
\hline$\varpi_{0}(870 \mathrm{~nm})$ & 0.78 & & 0.78 \\
$g(870 \mathrm{~nm})$ & 0.58 & $\mathbf{0 . 7 4}$ & 0.58 \\
$\tau(870 \mathrm{~nm})$ & 0.12 & 0.58 & $\mathbf{0 . 1 1 5}$ \\
$\varpi_{0}(500 \mathrm{~nm})$ & 0.814 & 0.12 & 0.814 \\
$g(500 \mathrm{~nm})$ & 0.60 & $\mathbf{0 . 7 8}$ & 0.60 \\
$\tau(500 \mathrm{~nm})$ & 0.247 & 0.60 & $\mathbf{0 . 2 3 7}$ \\
$E A E$ & 1.3 & 0.247 & 1.3 \\
$A A E$ & 1.0 & 1.3 & 1.0 \\
TOA forcing $\left(\mathrm{W} / \mathrm{m}^{2}\right)$ & -2.3 & 1.0 & -2.2 \\
\hline
\end{tabular}

\subsection{Uncertainties}

Measurement and modeling uncertainties need to be assessed to obtain credible model evaluations (e.g., Bates et al., 2006). There are a number of potential sources of random error, including the assumptions made in the module, errors in the input data, and sampling errors associated with the measurements, as well as possible systematic errors that may be difficult to specify. In the following section we give quantitative estimates of likely random errors when that is possible, and follow with a brief discussion of two potential sources of systematic errors.

We subdivide the random errors into two classes: those associated with module assumptions, and those associated with measurements. We first discuss the assumptions made in the module. These include:

1. Aerosol shape and morphology. The module treats aerosols as spherical particles with a shell/core configuration, but the actual aerosols found in MCMA, as shown by scanning and transmission electron micrographs, are much more complex (Doran et al., 2008; Adachi and Buseck, 2008; Adachi et al., 2007). A detailed treatment of aerosol shells with non-spherical, and possibly tortured shapes, random inclusions of BC, and complex morphologies is not possible in current models, and simplification is thus required. Fuller et al. (1999) attempt to account for the random positioning of BC encapsulated by a spherical sulfate shell, and the resulting BC specific absorption is less than pure shell/core configuration by about $15 \%$. With that study in mind we estimate a random error of $\pm 15 \%$ to $B_{\text {scat }}$ and $B_{\text {abs }}$ to account for the departure from a shell/core configuration.
2. Assumptions regarding chemical species density. In the module each chemical constituent is assigned a density. For BC, Bond and Bergstrom (2006) state the plausible density range extends from 1.7 to $1.9 \mathrm{~g} / \mathrm{cm}^{3}$, and we have chosen the midpoint of this range as our density value for $\mathrm{BC}$. Using their range to define the extent of the possible error, we estimate the possible error to be about $\pm 5 \%$. Because little information is available about the density ranges of other substances, we assume that this error is applicable to other densities as well, and we consider the error random. Note, however, that if there is discrepancy between the assigned density and the actual, average density, this would result in a systematic error of unknown magnitude.

3. Assumptions regarding the refractive index. For BC, Bond and Bergstrom (2006) defined a range of plausible complex refractive indexes at $550 \mathrm{~nm}$, with the real part, $n$, ranging from 1.75 to 1.95 , and the complex part, $k$, ranging from 0.63 to 0.79 . Again, we chose the midpoint of these values and, consistent with their range of values, assumed random errors of $\pm 5 \%$ and $\pm 11 \%$ for $n$ and $k$, respectively. For various organic compounds, Kanakidou et al. (2005) report ranges of $n$ extending from about 1.35 to 1.75 (for a wavelength range of about $300 \mathrm{~nm}$ to $800 \mathrm{~nm}$ ), but with most compounds falling in a smaller interval, from 1.40 and 1.55. Accordingly, we take the uncertainty for $n$ of $\mathrm{OM}$ to be $\pm 5 \%$ and assign this same level of uncertainty to $n$ for inorganic compounds. These latter compounds are assumed to be non-absorbing and $k$ is set equal to zero. For the refractive index of dust, Mishra and Tripathi (2008) show a range of possible values at $870 \mathrm{~nm}$, with a large percent 
variation in the complex part and much less variation in the real part. Prasad and Singh (2007), and references therein, discuss possible values for the refractive index of dust suspended over the Indo-Gangetic plain. Using AERONET data, the range in refractive indices for dusty days was, for $n, 1.51$ to 1.60 , and for $k, 0.0011$ to 0.0033 , at a wavelength of $873 \mathrm{~nm}$. Lacking more precise information about optical properties of dust in the MCMA area, we take the refractive index of dust to be the midpoint of these ranges, with errors of $\pm 5 \%$ and $\pm 100 \%$ for the real and imaginary parts, respectively. The large percent error on the imaginary component is not a significant problem in the current evaluation because the absorption is dominated by black carbon.

4. The conversion of organic carbon mass to organic matter mass. Various studies (Aiken et al., 2008; DeCarlo et al., 2008; Malm et al., 2005; Turpin and Lim, 2001) have suggested values of the conversion factor ranging from 1.4 to 2.3 , depending on the type of aerosol considered. The most relevant study for our work is probably that of Aiken et al. (2008), who reported an average value of 1.71 at the $T_{0}$ site. Given that $\mathrm{T} 1$ is also primarily urban in character, we assumed a value of 1.7 , with an uncertainty of \pm 0.2 .

Measurement uncertainties come into play with both input data (e.g., chemical masses) and the PAS. Some of these uncertainties have been briefly mentioned above but for convenience we repeat them here. These errors include:

1. Errors in the PAS measurements. The magnitudes of these errors, for the PAS instrument at the T1 site, are $\pm 15 \%$ and $\pm 10 \%$ for $B_{\text {scat }}$ and $B_{\text {abs }}$, respectively.

2. Sampling efficiency of the PAS. It is assumed that particles with aerodynamic diameter larger than 2 to $3 \mu \mathrm{m}$ were not sampled. However, the sampling efficiency was not precisely quantified, thus generating an error of unknown but presumably small magnitude.

3. Errors in the measurements of $\mathrm{PM}_{2.5}$ chemical masses used as input data. For the PILS instrument used to sample inorganic species, the uncertainty of the measurements is given as $\pm 10 \%$ (Weber et al., 2001). The estimated uncertainty of the OC/EC instrument is $\pm 0.2 \mu \mathrm{g} / \mathrm{m}^{3}$, and the uncertainty in the $\mathrm{PM}_{2.5}$ mass measurements from the TEOM instrument is $\pm 5 \%$.

4. Size distribution measurement errors. Errors in number concentrations are $\pm 10 \%$ for each size channel, similar to what has been reported for other size measuring instruments (e.g., Wang et al., 2002). As previously mentioned, there is an additional, unknown error because of the extrapolation necessary to extend the size distribution from $0.735 \mu \mathrm{m}$ to larger sizes. The magnitude of this error can be estimated by changing the magnitude of the portion of the size distribution that is extrapolated. For example, if the extrapolated part of the volume distribution in the top (bottom) panel of Fig. 3 is multiplied by a factor of two, the scattering increases by $24 \%(5 \%)$.

If these errors are indeed random, then when averages are taken some error cancellation will occur. We estimated the overall random error by taking a Monte Carlo approach (Bevington and Robinson, 1992). We assumed all the errors were uncorrelated, and perturbed the variables in question (i.e., density, refractive index, morphology error, etc.) using normal deviates, where the standard deviation of the deviate distribution is assumed to be the random error estimates given above. We then ran the module 50000 times and found the distributions of $B_{\text {scat }}, B_{\text {abs, }}$ and $\varpi_{0}$. The widths of the distributions, the standard deviations, were taken as estimates of the random errors in the results. This technique is very rapid, avoids a tedious propagation of error analysis, and has been used to evaluate errors in inferred OM mass absorption coefficients (Barnard et al., 2008). The resulting random errors are $\pm 3.4 \mathrm{Mm}^{-1}$ for $B_{\text {scat }}$ and $\pm 1.2 \mathrm{Mm}^{-1}$ for $B_{\text {abs, }}$. For $\varpi_{0}$ the random error is \pm 0.03 .

Systematic errors are more difficult to deal with because they can be difficult to specify. Averaging in general does not reduce systematic errors, although some error reduction can occur because systematic errors of different sign will at least partially cancel. However, systematic errors might explain certain discrepancies between measured and observed optical properties. For example, within each of the 8 model bins, the aerosols are assumed to be internally mixed. Based on a detailed examination of individual particles sampled in the Mexico City plume, Adachi and Buseck (2008) assert that the internal mixing assumption is "relatively reliable for modeling," but Doran et al. (2008) find that at the T1 site, coating of $\mathrm{BC}$ particles progresses rapidly during the daylight hours but is limited or even absent during the night. Uncoated BC has a specific absorption of about $7.5 \mathrm{~m}^{2} / \mathrm{g}$ at $550 \mathrm{~nm}$ (Bond and Bergstrom, 2006), and at the T1 site, the measured specific absorption is close to this value in the early morning hours and increases to about $11 \mathrm{~m}^{2} / \mathrm{g}$ by noon (Doran et al., 2008). We use this finding to estimate the error in neglecting externally mixed $\mathrm{BC}$; the estimated error is $11 \mathrm{~m}^{2} / \mathrm{g} \div 7.5 \mathrm{~m}^{2} / \mathrm{g} \approx 1.5$, or up to $50 \%$ error in the calculation of $B_{\text {abs }}$, if all the BC is externally mixed. This error is systematic, and would occur in the morning where a significant fraction of the BC load is probably externally mixed. In fact, examination of the bottom panel of Figure 5 shows that there are many cases of early morning spikes in $B_{\text {abs }}$ where the calculated $B_{\text {abs }}$ (assumed internally mixed) exceeds the measured $B_{\text {abs }}$ (perhaps external mixed) by a large amount. A striking case is the absorption spike on day 80 (21 March 2006), when the observed and calculated values of $B_{\text {abs }}$ are about $35 \mathrm{Mm}^{-1}$ and $55 \mathrm{Mm}^{-1}$, respectively. 
Another possible source of systematic error is the attribution of the residual between $\mathrm{PM}_{2.5}$ mass and the sum of all other aerosol mass to dust. We examine the possible magnitude of this error by modifying the density and refractive index of the material we assume is dust. Instead of assigning this material the properties of dust (density $=2.6 \mathrm{~g} / \mathrm{cm}^{3}$; refractive index $=1.55+\mathrm{i} 0.002$ ), we let the density be 1.8 $\mathrm{g} / \mathrm{cm}^{3}$ and set the complex part of the refractive index equal to zero. This calculation reveals that the average value of $B_{\text {scat }}$ increases from $30.4 \mathrm{Mm}^{-1}$ to $31.1 \mathrm{Mm}^{-1}$, while $B_{\text {abs }}$ decreases from $11.7 \mathrm{Mm}^{-1}$ to $11.0 \mathrm{Mm}^{-1}$. The single scattering albedo changes from 0.74 to 0.76 . These are not large errors. The fact that the aerosol volumes derived from the chemical data and SMPS are similar (Fig. 4) further suggests that possible errors arising from the effects of fine mode dust are not likely to be significant.

The measurement uncertainties for $B_{\text {abs }}$ and $B_{\text {scat }}$ are $10 \%$ and $15 \%$, respectively, which leads to an uncertainty of about $6 \%$ in $\varpi_{0}$. The second and third columns of Table 2 show the calculated and observed value of these quantities, along with associated uncertainties. Averaged over the full ten-day period, the simulations and measurements agree within estimated uncertainties. The agreement is not as good if averages are taken over the two distinct meteorological regimes that subdivide the full ten-day period, but the agreement between observed and calculated values still falls within the stated uncertainty ranges for $B_{\text {scat }}$ for both periods and for $B_{\text {abs }}$ during the showery period. These averages are also shown in Table 2.

The differences between calculated and observed aerosol optical properties as listed in Table 2 will lead to errors in aerosol direct radiative forcing. These errors can be estimated using the method described in McComiskey et al. (2008). We define the top of atmosphere (TOA) aerosol broadband forcing, $F$, in the conventional manner, $F=\left(f_{a} \downarrow-f_{a} \uparrow\right)-\left(f_{0} \downarrow-f_{0} \uparrow\right)$, where $\left(f_{a} \downarrow-f_{a} \uparrow\right)$ denotes the net instantaneous downwelling shortwave broadband flux at the TOA in the presence of aerosols, and $\left(f_{0} \downarrow\right.$ $-f_{0} \uparrow$ ) is the net instantaneous downwelling TOA flux without aerosols. Following McComiskey et al., we find the average solar forcing, $F_{S \text {, ave }}$, where the average is taken over $24 \mathrm{~h}$ at the equinox. The flux calculations are made using the SBDART model (Ricchiazzi et al., 1998), with atmospheric conditions typical for the T1 site. The base case aerosol optical properties represent plausible values for the $\mathrm{T} 1$ site, and are specified at $870 \mathrm{~nm}$ : optical depth, $\tau=0.12$; asymmetry parameter, $g=0.58$; extinction angstrom exponent $(\mathrm{EAE})=1.3$, absorption angstrom exponent $(\mathrm{AAE})=1.0$, and $\varpi_{0}=0.78$. The value specified for $\varpi_{0}$ is the observed surface value, and we assume that it is constant throughout the depth of the atmosphere. The surface spectral albedo for the $\mathrm{T} 1$ site is from the analysis of Coddington et al. (2008).

SBDART input variables, and the TOA forcings are listed in Table 4, for: (1) case one, the base case, (2) case two, same as the base case, except $\varpi_{0}$ is set equal to the WRF-
Chem module calculated value of 0.74 instead of the observed value of 0.78 , and (3) case three, same as the base case, except the observed $\tau(=0.12)$ is scaled by the factor $B_{\text {ext, calculated }} / B_{\text {ext, observed }}\left(=42.1 \mathrm{Mm}^{-1} / 43.8 \mathrm{Mm}^{-1}=0.96\right)$, where $B_{\text {ext,calculated }}$ and $B_{\text {ext,observed }}$ are the average extinction coefficients calculated from the module and the observations, respectively. Here we assume that the surface scaling of extinction can be uniformly extrapolated throughout the atmosphere.

For the base case, the TOA forcing is $-2.3 \mathrm{~W} / \mathrm{m}^{2}$. For case two, the forcing is $-0.86 \mathrm{~W} / \mathrm{m}^{2}$, a difference of about $1.4 \mathrm{~W} / \mathrm{m}^{2}$ from the base case. The difference between the base case and case three is negligible. McComiskey et al. (2008) state that the largest contributor to forcing uncertainty is $\varpi_{0}$ and this is consistent with our results. The $1.4 \mathrm{~W} / \mathrm{m}^{2}$ difference is somewhat greater than the maximum uncertainty in TOA forcing, $1.1 \mathrm{~W} / \mathrm{m}^{2}$, as estimated by McComiskey et al. (2008) (e.g., see Table 4 in McComiskey et al.). However, when making this comparison, we must be mindful that they considered other sources of uncertainty, in addition to just $\varpi_{0}$ and $\tau$.

\section{Conclusions}

This study was originally motivated by the failure of the WRF-Chem model, run with full prognostic chemistry, to simulate $\varpi_{0}$ satisfactorily over the MILAGRO T1 site over a 10-day period. To help identify the source of the discrepancy, we extracted the WRF-Chem "aerosol chemistry to aerosol optical properties" module from the full WRF-Chem code and used observed (rather than simulated) values of aerosol chemical species and size distributions as input to the module. We then tested its ability to simulate the observed T1 aerosol optical properties $B_{\text {scat }}, B_{\mathrm{abs}}$, and $\varpi_{0}$ at a wavelength of $870 \mathrm{~nm}$.

Although some difficulties with the "aerosol chemistry to aerosol optical properties" module were found, we conclude that any shortcomings in the module are unlikely to have been a major factor in the discrepancies with the observed values of $\varpi_{0}$ found using the full WRF-Chem model. A more significant source of error likely is the difficulty of specifying emissions accurately. For example, the full WRFChem model gave an average value of $\varpi_{0}$ of 0.87 . Fast et al. (2009) showed that simulated BC was usually lower than observed, particularly between 11:00 and 16:00 UTC, with a bias of $-1.3 \mu \mathrm{g} / \mathrm{m}^{3}$ during the entire MILAGRO campaign. When the observed $\mathrm{BC}$ mass concentrations at $\mathrm{T} 1$ were substituted into the full simulation (not shown), replacing the simulated values derived from the emissions inventory estimates used as model input, the simulated mean value for $\varpi_{0}$ decreases to 0.78 , which is a the same as the observed mean value of 0.78 . Moreover, a significant portion of the diurnal variation in $\varpi_{0}$ was then simulated. This suggests that poor specification of $\mathrm{BC}$ emissions may be the primary cause for 
the poor $\varpi_{0}$ simulation by WRF-Chem. However, for the showery case, WRF-Chem overpredicts $\mathrm{PM}_{2.5}$ mass, leading to an overprediction of scattering and therefore $\varpi_{0}$. This shows that predicted $\mathrm{PM}_{2.5}$ mass also plays a role in determining aerosol optical properties. When the aerosol module alone was evaluated using measured chemical species and size distributions as input, the average simulated value of $\varpi_{0}$ was 0.74 , and the diurnal variation was captured reasonably well.

On an hour-by-hour basis the aerosol module does not perform satisfactorily in predicting $\mathrm{B}_{\text {scat }},\left(r^{2}=0.16\right)$, but does considerably better for $B_{\mathrm{abs}},\left(r^{2}=0.82\right)$ and $\varpi_{0}\left(r^{2}=0.56\right)$. The observed (and pronounced) diurnal patterns in $B_{\text {abs }}$ and $\varpi_{0}$ were approximately captured by the module (see Figs. 5 and 6), although the module tends to predict higher values of $B_{\text {abs }}$ in the morning (around 06:00 LST), when the concentration of $\mathrm{BC}$ is largest. We suggest this may arise because the module's assumption of full internal mixing in each bin is not appropriate during the morning hours.

The module shows better skill in simulating all three optical properties when averages over the 10-day period are considered, as summarized in Table 2. This table shows that: (1) for $B_{\text {scat }}$, the observed and calculated values are $34.1 \pm 5.1 \mathrm{Mm}^{-1}$ and $30.4 \pm 3.4 \mathrm{Mm}^{-1}$, respectively; (2) for $B_{\text {abs }}$, the observed and calculated values are $9.7 \pm 1.0 \mathrm{Mm}^{-1}$ and $11.7 \pm 1.2 \mathrm{Mm}^{-1}$; and (3) the observed and calculated $\varpi_{0}$ values are $0.78 \pm 0.05$ and $0.74 \pm 0.03$. These values include estimated uncertainties in the averages due to random error, as discussed in Sect. 3.2. Our estimate of the uncertainty in averaged, TOA aerosol forcing, attributable to module inaccuracies in calculating $\varpi_{0}$ and $B_{\text {ext }}$, is $1.4 \mathrm{~W} / \mathrm{m}^{2}$. The bulk of this uncertainty is induced by the difference between calculated and observed $\varpi_{0}$.

For climate simulations where hour-by-hour variations are less important, the current "aerosol chemistry to aerosol optical properties" module may be satisfactory and could prove to be quite useful. Significant improvement to the module simulations may be realized when a two-dimensional size distribution is used that considers the size of the aerosol as a whole, as well as the size of the $\mathrm{BC}$ inclusions (Zaveri et al., 2010; Oshima et al, 2009). For studies of more episodic events, additional work will be required to identify and correct the current shortcomings of the module, particularly in regard to the scattering calculations. Further testing, using data from other locations, would also be useful to determine how well the module performs with other mixtures of aerosols and higher relative humidity. Because the aerosols in the MCMA are dry, we do not know how well the module would perform in areas with large relative humidity and concomitant hydroscopic growth.

Acknowledgements. This research was supported by the US Department of Energy's Atmospheric Science Program (Office of Science, BER) under Contract DE-AC06-76RLO 1830 at Pacific Northwest National Laboratory. The Pacific Northwest National
Laboratory is operated by Battelle for the US Department of Energy. The authors wish to thank Elaine Chapman for her comments regarding this work, the AERONET program and Barry Lefer for the aerosol size distribution information, and Prof. Rodney Weber for the PILS data. We also thank Nels Laulainen, Mikhail Pekhour, Chris Doran, and Xiao-Xing Yu for their help during the MILAGRO field campaign; and Luisa Molina for organizing and running the campaign. We also thank Arturo Quirantes Sierra for his efficient shell/core Mie code. Finally, we thank Nancy Burleigh for her fine editorial job.

Edited by: T. Kirchstetter

\section{References}

Ackerman, T. P. and Toon, O. B.: Absorption of visible radiation in atmosphere containing mixtures of absorbing and non-absorbing particles, Appl. Optics, 20(20), 3661-3662, 1981.

Adachi, K., Chung, S. H., Friedrich, H., and Buseck, P. R.: Fractal parameters of individual soot particles determined using electron tomography: Implication for optical properties, J. Geophys. Res., 112, D14202, doi:10.1029/2006JD008296, 2007.

Adachi, K., and Buseck, P. R.: Internally mixed soot, sulfates, and organic matter in aerosol particles from Mexico City, Atmos. Chem. Phys., 8, 6469-6481, doi:10.5194/acp-8-6469-2008, 2008.

Aiken, A. C., DeCarlo, P. F., Kroll, J. H., Worsnop, D. R., Huffman, J. A., Docherty, K. S., Ulbich, I. M., Mohr, C., Kimmel, J. R., Sueper, D., Sun, Y., Zhang, Q., Trimborn, A., Northway, M., Ziemann, P. J., Canagaratna, M. R., Onasch, T. B., Alfarra, M. R., Prevot, A. S. H., Dommen, J., Duplissy, J., Metzer, A., Baltensperger, U., and Jiminez, J. L., O/C and OM/OC ratios of primary, secondary, and ambient organic aerosols with high-resolution time-of-flight aerosol mass spectrometer, Environ. Sci. Tech., 42, 4478-4485, 2008.

Arnott, W. P., Moosmüller, H., Rogers, C. F., Jin, J., and Bruch, R.: Photoacoustic spectrometer for measuring light absorption by aerosol: instrument description, Atmos. Environ., 33, 28452852, 1999.

Arnott, W. P., Moosmüller, H., and Walker, J. W., 2000: Nitrogen dioxide and kerosene-flame soot calibration of photoacoustic instruments for measurement of light absorption by aerosol, Rev. Sci. Instrum., 71, 4545-4552, 2000.

Barnard, J. C., Chapman, E. G., Fast, J. D., Schemlzer, J. R., Slusser, J. R., and Shetter, R. E.: An evaluation of the FAST-J photolysis algorithm for predicting nitrogen dioxide photolysis rates under clear and cloudy sky conditions, Atmos. Environ., 38, 3393-3403, 2004.

Barnard, J. C., Volkamer, R., and Kassianov, E. I.: Estimation of the mass absorption cross section of the organic carbon component of aerosols in the Mexico City Metropolitan Area, Atmos. Chem. Phys., 8, 6665-6679, doi:10.5194/acp-8-6665-2008, 2008.

Bates, T. S., Anderson, T. L, Baynard, T., Bond, T., Boucher, O., Carmichael, G., Clarke, A., Erlick, C., Guo, H., Horowitz, L., Howell, S., Kulkarni, S., Maring, H., McComiskey, A., Middlebrook, A., Noone, K., O’Dowd, C. D., Ogren, J., Penner, J., Quinn, P. K., Ravishankara, A. R., Savoie, D. L., Schwartz, S. E., Shinozuka, Y., Tang, Y., Weber, R. J., and Wu, Y.: Aerosol direct radiative effects over the northwest Atlantic, northwest Pacific, 
and North Indian Oceans: estimates based on in-situ chemical and optical measurements and chemical transport modeling, Atmos. Chem. Phys., 6, 1657-1732, doi:10.5194/acp-6-1657-2006, 2006.

Bergstrom, R. W., Pilewskie, P., Russell, P. B., Redemann, J., Bond, T. C., Quinn, P. K., and Sierau, B.: Spectral absorption properties of atmospheric aerosols, Atmos. Chem. Phys., 7, 5937-5943, doi:10.5194/acp-7-5937-2007, 2007.

Bergstrom, R. W., Schmidt, K. S., Coddington, O., Pilewskie, P., Guan, H., Livingston, J. M., Redemann, J., and Russell, P. B.: Aerosol spectral absorption in the Mexico City area: results from airborne measurements during MILAGRO/INTEX B, Atmos. Chem. Phys., 10, 6333-6343, doi:10.5194/acp-10-63332010, 2010.

Bevington, P. R. and Robinson, D. K.: Data Reduction and error analysis for the physical sciences, McGraw Hill, Boston, USA, 1992.

Birch, M. E. and Cary, R. A.: Elemental carbon-based method for monitoring occupational exposures to particulate diesel exhaust, Aerosol Sci. Technol., 25, 221-241, 1996.

Bond, T. C., Habib, G., and Bergstrom, R. W.: Limitations in the enhancement of visible light absorption due to mixing state, J. Geophys. Res., 111, D20211, doi:10.1029/2006JD007315, 2006.

Bond, T. C. and Bergstrom, R. W.: Light absorption by carbonaceous particles: An investigative review, Aerosol Sci. Tech, 40, 27-67, 2006.

Chapman, E.G., Gustafson, W. I., Easter, R. C., Barnard, J. C., Ghan, S. J., Pekour, M. S., and Fast, J. D.: Coupling aerosolscloud-radiative processes in the WRF-chem model: Investigating the radiative impact of large point sources., Atmos. Chem. Phys., 9, 945-964, doi:10.5194/acp-9-945-2009, 2009.

Chou, M. D., Suarez, M. J., Ho, C. H., Yan, M. M. H., and Lee, K. T.: Parameterizations for cloud overlapping and shortwave single-scattering properties for use in general circulation and cloud ensemble models, J. Clim., 11, 202-214, 1998.

Coddington, O., Schmidt, K. S., Pilewskie, P., Gore, W. J., Bergstrom, R. W., Román, M. O., Redemann, J., Russell, P. B., Liu, J., and Schaaf, C. B.: Aircraft measurements of spectral surface albedo and its consistency with ground-based and space-borne observations, J. Geophys. Res., 113, D17209, doi:10.1029/2008JD010089, 2008.

DeCarlo. P. F., Slowik, J. G., Worsnop, D. R., Davidovits, P., and Jimenez, J. L.: Particle morphology and density characterization by combined mobility and aerodynamic diameter measurements. Part 1: Theory: Aerosol Sci. Tech., 38, 1185-1205, 2004.

DeCarlo, P. F., Dunlea, E. J., Kimmel, J. R., Aiken, A. C., Sueper, D., Crounse, J., Wennberg, P. O., Emmons, L., Shinozuka, Y., Clarke, A., Zhou, J., Tomlinson, J., Collins, D. R., Knapp, D., Weinheimer, A. J., Montzka, D. D., Campos, T., and Jiminez, J. L.: Fast airborne aerosol size and chemistry measurements above Mexico City and Central Mexico during the MILAGRO campaign, Atmos. Chem. Phys., 8, 4027-4048, doi:10.5194/acp8-4027-2008, 2008.

Doran, J. C., Barnard, J. C., Arnott, W. P., Cary, R., Coulter, R., Fast, J. D., Kassianov, E. I., Kleinman, L., Laulainen, N. S., Martin, T., Paredes-Miranda, G., Pekhour, M. S., Shaw, W. J., Smith, D. F., Springston, S. R., and Yu, X.-Y.: The T1 - T2 study: Evolution of aerosol properties downwind of Mexico City, Atmos. Chem. Phys., 7, 1585-1598, doi:10.5194/acp-7-1585-2007, 2007a.

Doran, J. C., Corrigendum to "The T1-T2 study: Evolution of aerosol properties downwind of Mexico City", Atmos. Chem. Phys., 7, 2197-2198, doi:10.5194/acp-7-2197-2007, 2007b.

Doran, J. C., Fast, J. D., Barnard, J. C., Laskin, A., Desyaterik, Y., and Gilles, M. K.: Applications of lagrangian dispersion modeling to the analysis of changes in the specific absorption of elemental carbon, Atmos. Chem. Phys., 8, 1377-1389, doi:10.5194/acp-8-1377-2008, 2008.

Fast, J. D., Gustafson, Jr., W. I., Easter, R. C., Zaveri, R. A., Barnard, J. C., Chapman, E. G., and. Grell, G. A.: Evolution of ozone, particulates, and aerosol direct forcing in an urban area using a new fully-coupled meteorology, chemistry, and aerosol model, J. Geophys. Res., 111, doi:10.1029/2005JD006721, 2006.

Fast, J. D., de Foy, B., Acevedo Rosas, F., Caetano, E., Carmichael, G., Emmons, L., McKenna, D., Mena, M., Skamarock, W., Tie, X., Coulter, R. L., Barnard, J. C., Wiedinmyer, C., and Madronich, S.: A meteorological overview of the MILAGRO field campaigns, Atmos. Chem. Phys., 7, 2233-2257, doi:10.5194/acp-7-2233-2007, 2007

Fast, J. D., Aiken, A., Alexander, L., Campos, T., Canagaratna, M., Chapman, E., DeCarlo, P., de Foy, B., Gaffney, J., de Gouw, J., Doran, J. C., Emmons, L., Hodzic, A., Herndon, S., Huey, G., Jayne, J., Jimenez, J., Kleinman, L., Kuster, W., Marley, N., Ochoa, C., Onasch, T., Pekour, M., Song, C., Warneke, C., Welsh-Bon, D., Wiedinmyer, C., Yu, X.-Y., and Zaveri, R.: Evaluating simulated primary anthropogenic and biomass burning organic aerosols during MILAGRO: Implications for assessing treatments of secondary organic aerosol, Atmos. Chem. Phys., 9, 6191-6215, doi:10.5194/acp-9-6191-2009, 2009.

Fuller, K. A., Malm, W. C., and Kreidenweis, S. M.: Effects of mixing on extinction by carbonaceous particles, J. Geophys. Res., 104(D13), 15941-15954, 1999.

Ghan, S. J. and Schwartz, S. E.: Aerosol properties and processes, B. Am. Meteorol. Soc., 88(7), 1059-1082, 2007.

Grell, G. A., Peckham, S. E., Schmitz, R., and McKeen, S. A., Frost, G., Skamarock, W. C., and Eder, B.: Fully coupled "online' chemistry within the WRF model, Atmos. Environ., 39, 69576976, 2005.

Gustafson Jr., W. I., Chapman, E. G., Ghan, S. J., and Fast, J. D.: Impact on modeled cloud characteristics due to simplified treatment of uniform cloud condensation nuclei during NEAQS 2004 Geophys. Res. Lett., 34, L19809, doi:10.1029/2007GL030021, 2007.

Kanakidou, M., Seinfeld, J. H., Pandis, S. N., Barnes, I., Dentener, F. J., Facchini, M. C., Van Dingenen, R., Ervens, B., Nenes, A., Nielsen, C. J., Swietlicki, E., Putaud, J. P., Balkanski, Y., Fuzzi, S., Horth, J., Moorgat, G. K., Winterhalter, R., Myhre, C. E. L., Tsigaridis, K., Vignati, E., Stephanou, E. G., and Wilson, J.: Organic aerosol and global climate modeling: A review, Atmos. Chem. Phys., 5, 1053-1123, doi:10.5194/acp-5-1053-2005, 2005.

Kirchstetter, T. W., Novakov, T., and Hobbs, P.: Evidence that the spectral dependence of light absorption by aerosols is affected by organic carbon, J. Geophys. Res., 109, D21208, doi:10.1029/2004JD004999, 2004.

Lack, D. A., Cappa, C. D., Baynard, T., Massoli, P., Covert, D. S., Sierau, B., Bates, T. S., Quinn, P. K., Lovejoy, E. R., and Ravis- 
hankara, A. R.: Bias in ?lter based aerosol absorption measurements due to organic aerosol loading: Evidence from ambient sampling, Aerosol Sci. Technol., 42(12), 1033-1041, 2008.

Lewis, K., Arnott, W. P., Moosmüller, H., and Wold, C. E.: Strong spectral variation of biomass smoke light absorption and single scattering albedo observed with a novel dual-wavelength photoacoustic instrument, J. Geophys. Res., 113, D16203, doi:10.1029/2007JD009699, 2008.

Malm, W. C., Day, D. E., Carrico, C., Kreidenweis, S. M., Collett, J. L., McMeeking, G., Lee, T., Carrillo, J., and Schichtel, B.: Intercomparison and close calculations using measurements of aerosol species and optical properties during the Yosemite Aerosol Characterization Study, J. Geophys. Res., 110, D14302, doi:10.1029/2004JD005494, 2005.

Marley, N. A., Gaffney, J. S., Castro, T., Salcido, A., and Frederick, J.: Measurements of aerosol absorption and scattering in the Mexico City Metropolitan Area during the 2006 MILAGRO field campaign: A comparison of results from the T0 and T1 sites, Atmos. Chem. Phys., 9, 189-206, doi:10.5194/acp-9-189-2009, 2009.

McComiskey, A., Schwartz, S. E., Schmid, B., Guan, H., Lewis, E. R., Ricchiazzi, P., and Ogren, J. A.: Direct aerosol forcing: Calculation from observables and sensitivities to inputs, J. Geophys. Res., 113, D09202, doi:10.1029/2007JD009170, 2008.

McKeen, S. Chung, S. H., Wilczak, J., Grell, G., Djalalova, I., Peckham, S., Gong, W., Bouchet, V., Moffet, R., Tang, Y., Carmichael, G. R., Mathur, R., and Yu, S: Evaluation of several $\mathrm{PM}_{2.5}$ forecast models using data collected during the ICARTT/NEAQS 2004 field study. J. Geophys. Res., 112, doi:10.1029/2006JD007608, 2007.

McKeen, S., Grell, G., Peckham, S., Wilczak, J., Djalalova, I., Hsie,, E. Y., Frost, G., Peischi, J., Schwarz, J., Spackman, R., Holloway, J., de Gouw, J., Warneke, C., Gong, W., Bouchet, V., Gaudreault, S., Racine, J., McHenry, J., McQueen, J., Lee, P., Tang, Y., Carmichael, G. R., and Mathur, R.: An evaluation of real-time air quality forecasts and their urban emissions over eastern Texas during the summer of 2006 Second Texas Air Quality field study. J. Geophys. Res., 114, D00F11, doi:10.1029/2008JD011697, 2009.

Mishra, S. K. and Tripathi, S. N.: Modeling optical properties of mineral dust over the Indian Desert, J. Geophys. Res., 113, D23201, doi:10.1029/2008JD010048, 2008.

Moffet, R. C., Qin, X., Rebotier, T., Furutani, H., and Prather, K. A.: Chemically segregated optical and microphysical properties of ambient aerosols measured in a single-particle mass spectrometer, J. Geophys. Res., 113, D12213, doi:10.1029/2007JD009393, 2008a.

Moffet, R. C., De Foy, B., Molina, L. T., Molina, M. J., and Prather, K. A.: Measurement of ambient aerosols in northern Mexico City by single particle mass spectrometry, Atmos. Chem. Phys., 8, 4499-4516, 2008b,

http://www.atmos-chem-phys.net/8/4499/2008/.

Orsini, D. A., Ma, Y., Sullivan, A., Sierau, B., Bauman, K., and Weber, R. J.: Refinements to the particle-into-liquid sampler (PILS) for ground and airborne measurements of water soluble aerosol concentration, Atmos. Environ., 37, 1243-1259, 2003.

Oshima, N., Koike, M., Zhang, Y., and Kondo, Y.: Aging of black carbon in outflow from anthropogenic sources using a mixing state resolved model: 2. Aerosol optical properties and cloud condensation nuclei activities, J. Geophys. Res., 114, D18202, doi:10.1029/2008JD011681, 2009.

Paredes-Miranda, G., Arnott, W. P., Jimenez, J. L., Aiken, A. C., Gaffney, J. S., and Marley, N. A.: Primary and secondary contributions to aerosol light scattering and absorption in Mexico City during the MILAGRO 2006 campaign, Atmos. Chem. Phys., 9, 3721-3730, doi:10.5194/acp-9-3721-2009, 2009.

Pöschl, U.: Aerosol particle analysis: challenges and progress, Anal. Bioanal. Chem., 375, 30-32, 2003.

Prasad, A. K. and Singh, R. P.: Changes in aerosol parameters during major dust storm events (2001-2005) over the Indo-Gangetic Plains using AERONET and MODIS data, J. Geophys. Res., 112, D09208, doi:10.1029/2006JD007778, 2007.

Querol, X., Pey, J., Minguillón, M. C., Pérez, N., Alastuey, A., Viana, M., Moreno, T., Bernabé, R. M., Blanco, S., Cárdenas, B., Vega, E., Sosa, G., Escalona, S., Ruiz, H., and Artíñano, B.: Pm speciation and sources in Mexico during the MILAGRO-2006 Campaign, Atmos. Chem. Phys., 8, 111-128, doi:10.5194/acp8-111-2008, 2008.

Quinn, P. K., Anderson, T. L., Bates, T. S., Dlugi, R., Heintzenberg, J., Hoyningen-Huene Von, W., Kulmala, M., Russell, P. B., and Swietlicki, E.: Closure in troposheric aerosol-climate research: a review and future needs for addressing aerosol direct shortwave radiative forcing, Contr. Atmos. Phys., 69, 547-577, 1996.

Rahmah, A. A., Arnott, W. P., and Moosmüller, H.: Integrating nehelometer with a low truncation angle and an extended calibration scheme, Meas. Sci. Technol., 17, 1723-1732, 2006.

Ricchiazzi, P., Yang, S., Gautier, C., and Sowle, D.: SBDART: A research and teaching software tool for plane-parallel radiative transfer in the Earth's atmosphere, B. Am. Meteorol. Soc., 79(10), 2101-2114, 1998.

Riemer N., West, M., Zaveri, R. A., and Easter, R. C.: Simulating the evolution of soot mixing state with a particleresolved aerosol model, J. Geophys. Res., 114, D09202, doi:10.1029/2008JD011073, 2009.

Shaw, W. J., Allwine, K. J., Fritz, B. G., Rutz, F. C., Rushel, J. P., and Chapman, E. G.: An evaluation of the wind erosion module in DUSTRAN, Atmos. Environ., 42, 1907-1921, 2008.

Sheridan, P. J., Arnott, W. P., Ogren, J. A., Andrews, A., Atkinson, D. B., Covert, D. S., Moosmüller, H., Petzold, A., Schmid, B., Strawa, A. W., Varma, R., and Virkkula, A.: The Reno Aerosol Optics Study: An evaluation of aerosol absorption measurement methods, Aerosol Sci. Tech., 39, 1-16, 2005.

Sokolik, I. N. and Toon, O. B.: Incorporation of mineralogical composition of aerosols into models of radiative properties of mineral aerosol from the UV to IR wavelengths, J. Geophys. Res., 104(D8), 9423-9444, 1999.

Subramanian, R., Roden, C. A., Boparai, P., and Bond, T. C.: Yellow beads and missing particles: Trouble ahead for filterbased absorption measurements, Aerosol Sci. Tech., 41, 630637, 2007.

Tie, X., Madronich, S., Li, G., Ying, Z., Weinheimer, A., Apel, E., and Campos, T.: Simulation of Mexico City plumes during the MIRAGE-Mex field campaign using the WRF-Chem model. Atmos. Chem. Phys., 9, 4621-4638, doi:10.5194/acp-9-4621-2009, 2009.

Turpin, B. J. and Lim, Ho-Jin: Species contributions to $\mathrm{PM}_{2.5}$ mass concentrations: revisiting common assumptions for estimating organic mass, Aerosol Sci. Tech., 35, 602-610, 2001. 
Wang, J., Flagan, R. C., Seinfeld, J. H., Jonsson, H. H., Collins, D. R., Russell, P. B., Schmid, B., Redemann, J., Livingston, J. M., Goa, S., Hegg, D. A., Welton, E. J., and Bates, D.: Clear-column radiative closure during ACE-Asia: Comparison of multi-wavelength extinction derived from particle size and composition with results from Sun photometry, J. Geophys. Res., 107(D23), 4688, doi:10.1029/2002JD002465, 2002.

Weber, R. J., Orsini, D., Daun, Y., Lee, Y.-N., Klotz, P. J., and Brechtel, F.: A particle-to-liquid collector for rapid measurement of aerosol bulk chemical composition, Aerosol Sci. Tech., 35, 718-727, 2001.

Wild, O., Zhu, X., and Prather, M. J.: Fast-J: Accurate simulation of in- and below-cloud photolysis in tropospheric chemical models, J. Atmos. Chem., 37, 245-282, 2000.

Wilczak, J. M., Djalaova, I., McKeen, S., Bianco, L., Bao, J. W., Grell, G., Peckham, S., Mathur, R., McQueen, J., Lee, P.: Analysis of regional meterology and surface ozone during the TexAQS II field program and evaluation of the NMM-CMAQ and WRF-Chem air quality models. J. Geophys. Res., 114, D00F14, doi:101029/2008JD011675, 2009.
Zaveri, R. A. and Peters, L. K.: A new lumped structure photochemical mechanism for large-scale applications, J. Geophys. Res., 104, 30387-30415, 1999.

Zaveri, R. A., Easter, R. C., Fast, J. D., and Peters, L. K.: Model for simulating aerosol interactions and chemisty (MOSAIC), J. Geophys. Res., 113, D13204, doi:10.1029/2007JD008782, 2008.

Zaveri, R. A., Barnard, J. C., Easter, R. C., Riemer, N., and West, M.: Particle-resolved simulation of aerosol size, composition, mixing state, and the associated optical and cloud condensation nuclei activation properties in an evolving urban plume, J. Geophys. Res., doi:10.1029/2009JD013616, in press, 2010. 